\title{
Practice Benefit from Participating in a Practice-based Research Network Study of Postpartum Depression: A National Research Network (NRN) Report
}

\author{
Barbara P. Yawn, MD, MSc, Wilson Pace, MD, Allen Dietrich, MD, \\ Susan Bertram, RN, MSN, Margary Kurland, RN, BSN, Deborah Graham, MPH, \\ Jessica Huff, MS, MPH, Liliana Rocca, MD, and Peter Wollan, PhD
}

Background: At the midpoint of a large clinical trial taking place in a practice-based research network (PBRN), we asked leaders of the enrolled practices about the impact of participating in a PBRN study.

Methods: Using semistructured interviews, the lead study nurse and physician from each site were queried about the impact of study participation on issues related to the study topic of postpartum depression (PPD) as well as any other impacts on the practice not directly related to PPD. From the results, initial themes were identified by 3 of the investigators (BPY, SB, MK) and confirmed by all the authors. Interviewee responses were grouped by theme.

Results: Forty-eight study leaders from 28 solo, moderately sized group and residency practices were interviewed during a period of 60 days. Practices were located in 20 different states, and $54 \%$ were in rural communities. Six major themes emerged. Study participation led to: (1) the recognition of the need for systematic approaches; (2) more effective teamwork and communication within the practice; (3) adaptation and extension of the PPD study tools and a systematic approach to the care of other chronic conditions; (4) increased professional self-worth and community recognition; (5) opportunity and support for staff members to "stretch" into new roles; and (6) increased research literacy within the practice.

Conclusions: Participating in a PBRN research study can provide advantages to practices that extend beyond the study's specific purpose and content. These results provide further support for the value of PBRN research funding. (J Am Board Fam Med 2010;23:455-464.)

Keywords: Practice-based Research, PBRN, Postpartum Depression

Practice-based research networks (PBRNs) have become common laboratories for translational and

This article was externally peer reviewed.

Submitted 23 October 2009; revised 18 January 2010; accepted 25 January 2010.

From the Department of Research, Olmsted Medical Center, Rochester, MN (BPY, SB, MK, LR, PW); the National Research Network, American Academy of Family Physicians, Leawood, KS (WP, DG, JH); and the Department of Community and Family Medicine, Dartmouth Medical School, Hanover, NH (AD).

Funding: Funding was provided by the Agency for Healthcare Research and Quality (grant no. R01 HS14744). Conflict of interest: none declared.

Corresponding author: Barbara P. Yawn, MD, MSc, Department of Research, Olmsted Medical Center, 210 Ninth Street SE, Rochester, MN 55904 (E-mail: byawn@olmmed.org).

\section{See Related Commentary on Page 440.}

clinical research, moving from simple card or observational studies to clinical trials and translational projects. ${ }^{1-12}$ The information and data collected from PBRN studies have led to changes in the medical approaches to conditions like spontaneous abortion, ${ }^{13}$ a better understanding of the spectrum of common and uncommon conditions, ${ }^{14-18}$ and new ways to approach chronic diseases. ${ }^{19-24}$ Practices often volunteer repeatedly to participate in PBRN studies, suggesting that the rewards of PBRN research are not limited to gathering data and publishing results but may also provide specific benefits to the practices. ${ }^{25-27}$ Few data have been published about the potential added benefits of PBRN research to the practices that are willing to give of their time, energy, and enthusiasm with little monetary compensation. ${ }^{28-30}$ The work that has been published generally focuses on benefits 
directly related to the topic of study for the practice, primary care, patients, or improved health policies. ${ }^{31-39}$ Few studies have addressed potential benefits for the practice that extend beyond the study topic. As PBRN studies move from simply recording events to evaluating new management strategies and systems, the potential benefits to the practices increase.

This study used semistructured interviews to ask practice leaders about benefits and problems they believe occurred as a result of participation in a PBRN study of screening, diagnosis, and management of postpartum depression (PPD). Inquiries addressed benefits and problems that related directly to the care of PPD, as well as practice and personal benefits and problems indirectly related or not at all related to PPD care, management, and study implementation. Here we have chosen to focus on the benefits-rather than burdens-reported by the PBRN members because few publications have focused on benefits; they often report only the burdens. These practices did report burdens related to time, institutional review board approval, and human subjects training, which have been reported in a previous article related to research approval issues. ${ }^{40}$

We believe the themes and quotes from this study of potential benefits will be useful for practices that currently are participating or are considering participating in PBRN work. These benefits should also be added to the list of reasons to increase funding for PBRN research from national funding agencies, such as the National Institutes of Health, the Agency for HealthCare Research and Quality, the Centers for Disease Control and Prevention, and other foundations and pharmaceutical companies.

\section{Methods}

This was a qualitative project nested within a randomized controlled trial of PPD screening, diagnosis, and management. Data were collected from all 28 sites using semistructured telephone interviews with members of the nursing and medical staff who served as the study lead personnel. A total of 48 people were interviewed.

\section{Description of the Parent Study}

The Translating Research into Practice for Postpartum Depression (TRIPPD) study is a random- ized controlled trial comparing standardized universal 2-step screening for PPD, followed by a recommended program of physician-driven therapy with structured follow-up using a combination of phone contacts and visits to usual care. The study is being conducted in 28 American Academy of Family Physicians National Research Network practices in 20 states spread widely across the United States. Included in the 28 practices are 12 family medicine residency programs and 15 rural private practices.

Interviews were conducted during a period of 60 days at the midpoint of the study when the initial intervention sites moved to maintenance status and the initial control sites implemented the intervention. Leaders from both intervention and control practices were interviewed. Approximately 1300 women had been enrolled across the sites at the time of these interviews. All interviews were conducted by telephone with one of the investigators and one or more of the study coordinators participating in each call.

The questions used for the interview are shown in Table 1. For each question, prompts were provided if the interviewee had no response. Prompts were also used to follow up on specific areas after the interviewee completed their initial response. Notes recording the interviewees' comments (using the interviewees' exact words) were made by a study team member. The interviewer and the central team note-taker submitted interview summaries and quotes within 24 hours of completion of the call.

After all interviews were completed, the notes from the interviews were collated. An immersion crystallization approach to analysis was used. ${ }^{41}$ Three of the authors (BPY, SB, MK) read all of the responses and developed an initial set of ideas expressed by the interviewees. The initial 3 reviewers then met and reviewed these ideas, developing an initial set of themes through iterative review and discussion. The interview reports, with the ideas highlighted from the 3 initial reviewers, were then read by the other authors to identify any suggestions for modifications and additions. Final agreement on the themes and illustrative quotes was reached during several conference calls with all team members. We kept the final 5 interviews from the initial theme analysis and found that they provided no new thematic information, although they provided additional specific examples of the theme, 
Table 1. Interview Guide for Lead Physician and Nurse at PBRN Sites

Question study, what has happened?
Subsequent/Follow-up Questions

2. Describe one positive change/ thing other than expanded or improved PPD care due to being part of this study?

3. Describe one negative change/ thing that has happened because of this study?

4. What has been your experience with other physicians/nurse practitioners/physician assistants as related to this study?

5. What has been your experience with the nursing staff related to this study?

6. What parts of the PPD program do you think you will continue to use after the study is over?

7. What would you say to investigators?

8. Would you do another PBRN study?

9. If you could only be in the control arm of the study, would you think it is worth your time and your clinics time to do this study?
A. Edinburgh Postnatal Depression Screen

B. 9-item Patient Heath Questionnaire (short depression screener)

C. Self-care

D. Follow-up calls

E. Follow-up visits
A. To your personal practice? Related to PPD care?

B. As a result of participating in this study, what has happened in your clinic specifically related to PPD care or management?

C. Would you describe this as a practice or system change?

D. As a result of participating in this study, what has happened in your clinic unrelated to PPD care or management?

What was a valuable/important change and was there anything negative you experienced?

As a result of this study, have there been any changes in the way your clinic has approached issues/problems, quality improvement, practice changeanything else?

Were there any other important changes?

Were there any other negatives?

A. What about their buy in?

B. Have you developed any new

C. What has happened with those who were initially amenable?

D. What has happened to those who

E. What barriers have you experienced with the other physicians/ nurse practitioners/physician assistants?

Only if not mentioned

PPD, postpartum depression; PBRN, practice-based research network. 
Figure 1. Geographic locations of the 28 primary care practices participating in the Translating Research into Practice for Postpartum Depression (TRIPPD) study.

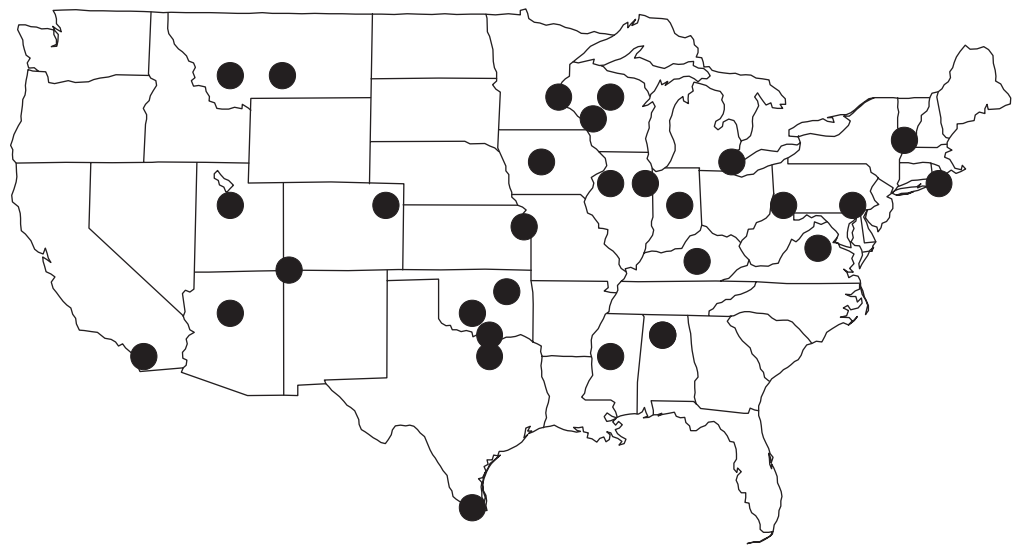


"After working on this project, our other quality improvement projects are being done more as a team-getting people together to solve problems."

"We have learned how to celebrate success-like when you sent us candy." "Initially we were not one big happy team." - Residency

"[Being in this study] has shown us the importance of using forms instead of trying to remember the right questions for everything." - Private practice

"We have begun to think more clearly about the importance of continuity of care for chronic conditions." —Residency

\section{Theme \#2: Participation Led to Increased and More Effective Teamwork and Communication Within the Practice}

This study's intervention required communication among receptionists, nursing staff, and physicians. In several practices, the business manager or supervisors were also part of the team. Highlighting the benefit of team communication and a team culture was well accepted by nearly all practices and was especially valued by the receptionist and nursing staff members. Communications were directly related to patient care rather than addressing paper work or the need to meet someone else's expectations.

\section{Examples of the Interviewee Responses}

"This study takes the whole practice and our nursing staff really buys in and is now developing a closer relationship with patients." - Residency

"We have developed a very cooperative spirit among staff." - Private practice

"We are working as a team now ... front office people are helping too." - Residency

"This has really helped team work overall." "The nurse calls helped a sense of team work." -Residency

"Physicians learned that the nursing staff can do more, like the follow-up phone calls. Working together better." - Community health clinic (CHC) and residency

\section{Theme \#3: Participation Led to Adaptation and Extension of the PPD Tools and a Systematic Approach to the Care of Other Chronic Conditions}

The TRIPPD study required practices to determine how to successfully collect clinical data about selected individuals before those individuals could be seen by their physician or other clinician; it also required other members of the office to participate in the active management of patients who had identified depression. The study also highlighted the importance of regular, scheduled care, including phone calls and visits for intervention patients. Some practices were able to apply these concepts to the care of other conditions.

\section{Examples of the Interviewee Responses}

This theme was best stated by one of the participants: "In family medicine we need to develop systems that work for more than one thing. We can't have screening tools and systems for every disease ... this works for all depression and might work for other chronic diseases too." —-Solo physician

"Those who have been supportive [of this study] all along want to move on to other systems now." $-\mathrm{CHC}$

"Dr. $\mathrm{X}$ is making phone calls for people with other problems." - Residency

"[We have begun] using the [9-item Patient Health Questionnaire] and guidelines for following PPD for all depression management in the practice." - CHC and residency

"We will use more calls [for patients with other conditions]. Patients seem to appreciate the calls." -Residency

"We are using the PPD medication sheets for all depression treatment and the [9-item Patient Health Questionnaire] too.” - Residency

"We learned about case management from this study-learned that it is not negative and we can use it for many conditions." - $-\mathrm{CHC}$ and residency

"One of the physicians has put this on his palm pilot. He is using the follow-up system for diabetes. It has gone to the practice development committee to decide how to make it system wide approach ... and [have the nurses make] calls to people with diabetes for follow up." - CHC and residency

"[We have learned to] use tools that the patient completes so the time with the doctor is more productive." - Residency

\section{Theme \#4: Participation Led to Increased Professional Self-Worth and Community Recognition}

Formal community recognition such as newspaper articles, stories on the local radio, or commendations from the local hospital or health department 
are not common in many rural or small family medicine practices. When such recognition did occur, the practice's entire staff felt they had been recognized as members of a national study that could improve care for women everywhere. Although the participation of many sites led to local or regional attention, some sites received national recognition for their work. Such organizational empowerment has been shown to enhance individual practice members' self-esteem and staff retention. $^{48-51}$

\section{Examples of the Interviewee Responses}

"We feel better about what we do and who we are. We are important enough to be in a national study and that made our staff feel better about themselves." - $\mathrm{CHC}$

"The [obstetrics/gynecology] staff at the local hospital want to work with us now [that we are part of this study]. The obstetricians want to help with this [study] and collaborate on other things. It feels good to teach [the specialists]." - Residency

"We have been asked to become members of the National Council for Community Behavioral Health Care specifically because we are doing this study." "The national committee has helped me become familiar with [the Health Resources and Services Administration] and [the National Institutes of Health] and other places. [The Health Resources and Services Administration] is very excited about what we are doing and has asked us to apply for a grant to pay for personnel to do onsite counseling and case management." - $\mathrm{CHC}$ and residency

"We have gained prestige in the community and the health system for being part of a well-planned and important federally funded trial with sites all over the country." - CHC.

"Showed me I can be part of an important study and get evidence for important topics." - Private practice

"My mother is proud of me for doing this study." - Lead physician in a private practice

\section{Theme \#5: Participation Led to "Stretching" the Roles of Various Staff Members}

The team leaders needed to learn new skills to help direct and manage the study within their practices. Nursing staff members were asked to do new things that led to new confidence and a new willingness to participate beyond their "jobs." Receptionists became an important part of the system. Increasing staff members' skill mix (learning and applying new skills) and staff empowerment have been shown to reduce staff stress and enhance staff retention. ${ }^{48-51}$ Physicians with academic appointments found that the project helped them better understand how research is accomplished and helped them to meet institutional demands for research. Some reported they would use this education in studies of their own or those sponsored by others in their centers.

\section{Examples of the Interviewee Responses}

"One resident has done a [Family Physicians Inquiry Network] answer on depression now." -Residency (Family Physicians Inquiry Network is a service for primary care physicians and reported as a section in the Fournal of Family Practice that answers practical questions.)

"One nursing staff was so inspired she went out to the Internet and found a poster to use in the rooms that were for the women." - Residency

"The social worker has become a big advocate. She has become very creative in finding help for those without insurance." - Residency

"The receptionists say they had been waiting for someone to ask them to help with more than check in." -Private practice

"Other faculty, in addition to the study leaders, have decided they need to participate in research and more actively in committees for [quality improvement]." - Residency

"We have worked with [Blue Cross Blue Shield] to get care for the uninsured and they have given money to visiting nurses who now also use the [Edinburgh Postnatal Depression Screen] and [the 9-item Patient Health Questionnaire].” - Residency

"[Participation] has helped me move along in my research career with greater support for all my research time from the program director." - Residency

"This has been a way to move my career to the place I would like to be-doing more than patient care and $[\mathrm{I}]$ especially learned how to improve practice and then assess if we really helped." - Residency 
"It gives me an academic outlet, beefs up my [curriculum vitae,] and is important for the residency review committee oversight." - Residency

\section{Theme \#6: Participation Led to Increased Research Literacy within the Practice}

Completion of the human subjects training, learning how to complete the informed consent process with patients, and learning how "new knowledge" is generated by research increased many staff members' comfort with research and their appreciation of how patients' rights were protected. Several agreed they would now be willing to be a research subject and, indeed, several were enrolled in this study. Physicians thought that participating in research helped all practice personnel better understand the concept of evidence-based medicine. Increased research literacy is a major goal of the National Institutes of Health and its agencies. The reports from these PBRN sites suggest that enhanced research literacy can be a valuable addition to the training of all health professionals, especially those who have had little first-hand exposure to clinical research.

\section{Examples of the Interviewee Responses}

“... It was helpful for the medical assistants to understand more about the protections that are used in research. I think they are more comfortable explaining to patients but also they say they tell their friends research is OK." "My staff is not afraid of research participation now." - $\mathrm{CHC}$

"For residents, we have given them a taste of research outside of academia and they like it. This has introduced them to PBRNs, it has shown them that to do research you do not have to feel "used" like in many studies that come from academic centers. What we are doing is better for our patients; we gain personally and so do the patients from being in PBRN research." - CHC and residency

"The residents learned a lot from human subjects training." - Residency

"Made it easier to do the next study." — Private practice

"Our hospital and clinic participated in "Sick Sigma" [sic] at the same time we started this study. Everyone hated that study and it almost killed everyone's interest in research. In turn they loved this study and people are now willing to believe that research is appropriate for practices and residency programs." —Residency
"Translational research is important and this is a good way to let the residents learn about research while doing a well-designed project. This has been a great success for our residents. Several say they will continue to do PBRN research practice." -Residency

\section{Discussion}

Participation in PBRN research seems to provide the opportunity for significant added value for practices and the people working within those practices. Added benefits affect patients, care systems, and individuals. These benefits to the research enterprise and to the generation of new knowledge published in journals are different from the benefits of practice-based research. ${ }^{1,3}$ In fact, the benefits seem to be different from the benefits people often assume practices will gain when research and quality improvement meet. ${ }^{7}$

For example, the health care professionals who participated in the PPD study reported translating the PPD system of care to related topics, such as the use of follow-up phone calls and standardized measures of disease status for patients with other chronic conditions. Although this is similar to what may happen in quality improvement work, it seems to go beyond the purpose and gains measured in many studies that are limited to the specific study topic. $^{22,23,31,32,39}$ Providing practices the tools and motivation to move to the next step has been the purported purpose of "quality collaboratives," but few have been shown to achieve that goal. ${ }^{52-54}$

Understanding the importance of systems of care and system support is the initial step in many facilitated models of practice improvement. ${ }^{55-57}$ The process of preparing for and participating in a research study seemed to help some practices reflect on their systems of care and allowed "sensemaking," eg, developing a broader overview of care processes to occur. ${ }^{57,58}$ This process of self-identification of practice gaps and problems as opposed to evaluation and critique by outside quality reports or assessors may lead to greater efforts to build on strengths and improve weaknesses. ${ }^{24,57-59}$ This is distinct from most pay-for-performance or external case manager assessments that identify weaknesses but seldom provide any tools or solutions to improve outcomes. ${ }^{60-62}$ Allowing practices the flexibility to implement and operationalize required study tasks, as is often done in PBRN and transla- 
tional research, seemed to empower these PBRN practices to use that problem-solving approach to address other practice needs or deficits.

Personal growth, whether described as "stretching" the staff or learning new skills to enhance interdisciplinary communication and team work, is often described as a long-term process requiring participation in many studies or at least many group meetings and Plan-Do-Study-Act cycles. ${ }^{52,53}$ Our study suggests that personal growth can also be attained by providing the practices with predesigned and pretested tools that require few changes to implement. ${ }^{5,24}$

Improved health and research literacy are described as a major goal of recent community-based research efforts from groups such as National Institute of Child Health and Human Development (request for application no. HD-03-012). This study seemed to enhance research literacy among practice personnel who were not usually considered part of the research core team, such as receptionists and medical assistants. We presented PPD diagnosis, management, and follow-up as a practice-wide change and staff at all levels became involved with the implementation of the intervention. This involvement seemed to increase health literacy and the buy-in on the part of all practice members to both this research study and to research in general.

This work may not be generalizable to all PBRN studies, especially those that are simply descriptive and not intended to study the effectiveness of new interventions or to translate evidence into everyday community practice. For example, it is unreasonable to expect all card studies of condition or process frequencies ${ }^{63,64}$ to promote systems thinking, empower staff, or enhance any care area. The data are based on perceptions from 28 sites but all were involved in a single study. The results may be dependent on the specific study design, which in this case was intended to be minimally intrusive to the practices and supported by a large research staff who developed positive relationships with the practice and study leaders during the course of the 3 years. This study is also longer than many PBRN studies and therefore allowed greater time for benefits to accrue to the practices and the health professionals.

\section{Conclusion}

PBRN research is crucial for the development and translation of new knowledge. It also seems that it can be beneficial to the rural, residency, and small community-based practices that chose to participate in this study.

\section{References}

1. Woolf SH. The meaning of translational research and why it matters. JAMA 2008;299:211-3.

2. van Weel C, Smith H, Beasley JW. Family practice research networks. Experiences from 3 countries. J Fam Pract 2000;49:938-43.

3. Westfall JM, Mold J, Fagnan L. Practice-based research - "Blue Highways" on the NIH roadmap. JAMA 2007;297:403-6.

4. Westfall JM, VanVorst RF, Main DS, Herbert C. Community-based participatory research in practice-based research networks. Ann Fam Med 2006; $4: 8-14$.

5. Kottke TE, Solberg LI, Nelson AF, et al. Optimizing practice through research: a new perspective to solve an old problem. Ann Fam Med 2008;6:459-62.

6. van Weel C. Longitudinal research and data collection in primary care. Ann Fam Med 2005;3(Suppl 1):S46-51.

7. Mold JW, Peterson KA. Primary care practice-based research networks: working at the interface between research and quality improvement. Ann Fam Med 2005;3(Suppl 1):S12-20.

8. van Weel C, van Weel-Baumgarten E, Mold J. The importance of longitudinal studies in family medicine: experiences of two practice-based research networks. J Am Board Fam Med 2006;19:69-74.

9. Kuo GM, Steinbauer JR, Spann SJ. Conducting medication safety research projects in a primary care physician practice-based research network. J Am Pharm Assoc (2003) 2008;48:163-70.

10. Lindbloom EJ, Ewigman BG, Hickner JM. Practicebased research networks: the laboratories of primary care research. Med Care 2004;42(4 Suppl):III45-9.

11. Anderko L, Bartz C, Lundeen S. Practice-based research networks: nursing centers and communities working collaboratively to reduce health disparities. Nurs Clin North Am 2005; 40:747-58, xi-xii.

12. Finch SA, Lalama C, Spino C, et al. Practice-based research network solutions to methodological challenges encountered in a national, prospective cohort study of mothers and newborns. Paediatr Perinat Epidemiol 2008;22:87-98.

13. Spontaneous abortion in primary care. A report from ASPN. J Am Board Fam Pract 1988;1:15-23.

14. Mold JW, Thompson DM. Management of brown recluse spider bites in primary care. J Am Board Fam Pract 2004;17:347-52.

15. Lydick E, Martin A, Yawn B. Impact of fears on quality of life in patients with a silent disease: osteoporosis. Clin Ther 1996;18:1307-15.

16. Cacy J, Mold JW. The clinical characteristics of brown recluse spider bites treated by family physi- 
cians: an OKPRN Study. Oklahoma Physicians Research Network. J Fam Pract 1999;48:536-42.

17. Yawn BP, Barrette BA, Wollan PC. Ovarian cancer: the neglected diagnosis. Mayo Clin Proc 2004;79: 1277-82.

18. Yawn BP, Saddier P, Wollan PC, St Sauver JL, Kurland MJ, Sy LS. A population-based study of the incidence and complication rates of herpes zoster before zoster vaccine introduction. Mayo Clin Proc 2007;82:1341-9.

19. Yawn BP, Wollan P, Kurland M, Scanlon P. A longitudinal study of the prevalence of asthma in a community population of school-age children. J Pediatr 2002;140:576-81.

20. Yawn B, Zyzanski SJ, Goodwin MA, Gotler RS, Stange KC. The anatomy of asthma care visits in community family practice. J Asthma 2002;39:71928.

21. Chandler JM, Martin AR, Girman C, et al. Reliability of an Osteoporosis-Targeted Quality of Life survey instrument for use in the community: OPTQoL. Osteoporos Int 1998;8:127-35.

22. Olson Al, Dietrich AJ, Prazar G, Hurley J. Brief maternal depression screening at well-child visits. Pediatrics 2006;118:207-16.

23. Dietrich AJ, Oxman TE, Williams JW, et al. Reengineering systems for the treatment of depression in primary care: cluster randomised controlled trial. BMJ 2004;329:602-9.

24. Yawn B, Bertram S, Wollan P. Introduction of Asthma APGAR tools improve asthma management in primary care practices. J Asthma Allergy. Available at http://www.dovepress.com/introduction-of-asthmaapgar-tools-improve-asthma-management-in-primarpeer-reviewed-article-JAA. Accessed 27 May 2010.

25. Tierney WM, Oppenheimer CC, Hudson BL, et al. A national survey of primary care practice-based research networks. Ann Fam Med 2007;5:242-50.

26. Fagnan LJ, Morris C, Shipman SA, Holub J, King A, Angier H. Characterizing a practice-based research network: Oregon Rural Practice-Based Research Network (ORPRN) survey tools. J Am Board Fam Med 2007;20:204-19.

27. Niebauer L, Nutting PA. Practice-based research networks: the view from the office. J Fam Pract 1994;38:409-14.

28. Love MM, Pearce KA, Williamson MA, Barron MA, Shelton BJ. Patients, practices, and relationships: challenges and lessons learned from the Kentucky Ambulatory Network (KAN) CaRESS clinical trial. J Am Board Fam Med 2006;19:75-84.

29. Goode JV, Mott DA, Chater R. Collaborations to facilitate success of community pharmacy practicebased research networks. J Am Pharm Assoc (2003) 2008;48:153-62.

30. Nyiendo J, Llyod C Haas M. Practice-based research: the Oregon Experience. J Manipulative Physiol Ther 2001;24:25-33.
31. Zafar A, Tierney W, Hickner J, Pace W. An adverse drug event and medication error reporting system for ambulatory care (MEADERS). AMIA Annu Symp Proc 2008;839-43.

32. Cifuentes M, Fernald DH, Green LA, et al. Prescription for health: changing primary care practice to foster healthy behaviors. Ann Fam Med 2005; 3(Suppl 2):S4-11.

33. Mold JW, Peterson KA. Primary care practice-based research networks: working at the interface between research and quality improvement. Ann Fam Med 2005;3(Suppl 1):S12-20.

34. Deshefy-Longhi T, Swartz MK, Grey M. Characterizing nurse practitioner practice by sampling patient encounters: an APRNet study. J Am Acad Nurse Pract 2008;20:281-7.

35. van Weel C, de Grauw W. Family practices registration networks contributed to primary care research. J Clin Epidemiol 2006;59:779-83.

36. Andrews JE, Pearce KA, Ireson C, Love MM. Information-seeking behaviors of practitioners in a primary care practice-based research network (PBRN). J Med Libr Assoc 2005;93:206-12.

37. Orzano A, Scott J, Hudson S, et al. Strategies for conducting complex clinical trials in diverse community practices. Medical Care 2007;45:1221-6.

38. Voorhees K, Fernald DH, Emsermann C, et al. Underinsurance in primary care: a report from the State Networks of Colorado Ambulatory Practices and Partners (SNOCAP). J Am Board Fam Med 2008; 21:309-16.

39. Young WF, McGloin J, Zittleman L, West DR, Westfall JM. Predictors of colorectal screening in rural Colorado: testing to prevent colon cancer in the high plains research network. J Rural Health 2007;23:238-45.

40. Yawn B, Graham D, Bertram S, et al. Practice-based research network studies and institutional review boards: two new issues. J Am Board Fam Med 2009; 22:453-60.

41. Crabtree BC, Miller WL, editors. Doing qualitative research. 2nd ed. Thousand Oaks, CA: Sage; 1999.

42. Finkelstein JA, Lozano P, Streiff KA, et al. Clinical effectiveness research in managed-care systems: lessons from the Pediatric Asthma Care PORT. Patient Outcomes Research Team. Health Serv Res 2002; 37:775-89.

43. Wagner EH, Glasgow RE, Davis C, et al. Quality improvement in chronic illness care: a collaborative approach. Jt Comm J Qual Improv 2001;27:63-80.

44. Pearson ML, Wu S, Schaefer J, et al. Assessing the implementation of the chronic care model in quality improvement collaboratives. Health Serv Res 2005; 40:978-96.

45. Solberg LI, Kottke TE, Brekke ML. Quality improvement in primary care: the role of organization, collaboratives, and managed care. In: McLaughlin $\mathrm{CP}$, Kalunzny AD, eds. Continuous quality improve- 
ment in head care: theory, implementation, and applications. 3rd ed. Gaithersburg, MD: Aspen Publishers; 2005:297-317.

46. Wagner EH. Chronic disease management: what will it take to improve care for chronic illness. Eff Clin Pract 1998;1:1-4.

47. Solberg LI. Guideline implementation: what the literature doesn't tell us. Jt Comm J Qual Improv 2000;26:525-37.

48. Kuo HT, Yin TJ, Li IC. Relationship between organization empowerment and job satisfaction as perceived by nursing assistants at long-term care facilities. J Clin Nurs 2008;17:3059-66.

49. Harrisson M, Loiselle CG, Duquette A, Semenic SE. Hardiness, work support and psychological distress among nursing assistants and registered nurses in Quebec. J Adv Nurs 2002;38:584-91.

50. Friesen D. Skill mix literature review. Healthc Manage Forum 1996;9:48-52.

51. Stearns SC, D'Arcy LP. Staying the course: facility and profession retention among nursing assistants in nursing homes. J Gerontol B Psychol Sci Soc Sci 2008;63:S113-21.

52. Bate SP, Robert G. Knowledge management and communities of practice in the private sector: lessons for modernizing the National Health Service in England and Wales. Public Admin 2002;80:243-63.

53. Øvretveit J, Bate P, Cleary P, et al. Quality collaboratives: lessons from research. Qual Saf Health Care 2002;11:345-51.

54. Lindenauer PK. Effects of quality improvement collaboratives. BMJ 2008;336:1448-9.
55. Cohen D, McDaniel RR, Crabtree BF, et al. A practice change model for quality improvement in primary care practice. J Healthc Manag 2004;49:15568, discussion 169-70.

56. Miller WL, Crabtree BF, McDaniel RR, Stange KC. Understanding change in primary care practice using complexity theory. J Fam Pract 1998;46:369-76.

57. Miller WL, McDaniel RR, Crabtree BF, Stange KC. Practice jazz: understanding variation in family practices using complexity science. J Fam Pract 2001;50: 872-8.

58. Peter M. Senge. The fifth discipline: the art and practice of the learning organization. New York: Random House; 1994.

59. Solberg LI. Improving medical practice: a conceptual framework. Ann Fam Med 2007;5:251-6.

60. Snyder L, Neubauer RL. Pay-for-performance principles that promote patient-centered care: an ethics manifesto. Ann Intern Med 2007;147:792-4.

61. Mandel KE, Kotagal UR. Pay for performance alone cannot drive quality. Arch Pediatr Adolesc Med 2007;161:650-5.

62. Foels T, Hewner S. Integrating pay for performance with educational strategies to improve diabetes care. Popul Health Manag 2009;12:121-9.

63. Green LA, Hickner J. A short history of primary care practice-based research networks: from concept to essential research laboratories. J Am Board Fam Med 2006;19:1-10.

64. Green LA, Hames CG Sr, Nutting PA. Potential of practice-based research networks: experiences from ASPN. J Fam Pract 1994;38:400-6. 